\title{
Implementation of an Integrative Oncological Concept in the Daily Care of a German Certified Breast Cancer Center
}

\author{
Friedemann Schad ${ }^{a, b}$ Anja Thronicke ${ }^{a}$ Antje Merkle ${ }^{a, b}$ Megan L. Steele ${ }^{a, c}$ \\ Matthias Kröz ${ }^{a, b, d, e} \quad$ Cornelia Herbstreit $^{b}$ Harald Matthes ${ }^{a, b}$
}

${ }^{a}$ Research Institute Havelhöhe, Berlin, Germany;

${ }^{b}$ Hospital Havelhöhe, Berlin, Germany;

'Institute of Health and Biomedical Innovation, School of Public Health and Social Work, Queensland University of Technology, Brisbane, Australia;

${ }^{\mathrm{d}}$ Institute for Social Medicine, Epidemiology and Health Economics, Charité - Universitätsmedizin Berlin, Berlin, Germany;

e Institute for Integrative Medicine, University of Witten/Herdecke, Witten/Herdecke, Germany

\section{Keywords}

Breast cancer center . Health services research

Integrative oncology · Viscum album L. · Anthroposophic medicine

\section{Summary}

Background: In recent decades the concept of integrative medicine has attracted growing interest in patients and professionals. At the Gemeinschaftskrankenhaus Havelhöhe (GKH), a hospital specialized in anthroposophical medicine, a breast cancer center (BCC) has been successfully certified for more than 5 years. The objective of the present study was to analyze how integrative strategies were implemented in the daily care of primary breast cancer patients. Methods: Clinical, demographic, and follow-up data as well as information on non-pharmacological interventions were analyzed. In addition, BCC quality measures were compared with data of the National Breast Cancer Benchmarking Report 2016. Results: Between 2011 and 2016, 741 primary breast cancer patients (median age 57.4 years) were treated at the GKH BCC. $91.5 \%$ of the patients showed Union for International Cancer Control (UICC) stage 0, I, II, or III and $8.2 \%$ were in UICC stage IV. $97 \%$ of the patients underwent surgery, $53 \%$ radiation, $38 \%$ had hormone therapy, and $25 \%$ received cytostatic drugs. $96 \%$ of the patients received non-pharmacological interventions and $32 \%$ received Viscum album L. therapy. Follow-up was performed in up to $93 \%$ of the patients 2 years after first diagnosis. Compared to nationwide benchmarking BCCs, the GKH BCC met the requirements in central items. Conclusions: The results of the present study show that integrative therapies of fered by the concept of anthroposophical medicine can be implemented in the daily care and treatment of a certified BCC. However, as national guidelines on integrative concepts in oncology are missing, further studies are needed for a systematic evaluation of integrative treatment and care concepts in this field.

(c) 2018 The Author(s). Published by S. Karger GmbH, Freiburg

\section{Schlüsselwörter}

Brustkrebszentrum · Versorgungsforschung · Integrative Onkologie . Viscum album L. . Anthroposophische Medizin

\section{Zusammenfassung}

Hintergrund: In den letzten Jahrzehnten findet das Konzept der integrativen Medizin wachsendes Interesse bei Patienten und Experten im Gesundheitswesen. Am Gemeinschaftskrankenhaus Havelhöhe (GKH), eine Klinik für anthroposophische Medizin, ist seit mehr als 5 Jahren ein zertifiziertes Brustkrebszentrum (BCC) etabliert. Ziel der vorliegenden Studie war es, die Umsetzung integrativer Behandlungskonzepte in der täglichen Krankenhausversorgung primärer Brustkrebspatienten eines zertifizierten BCC darzustellen. Methoden: Klinische und demographische Daten sowie Informationen zur Nachsorge und zu nichtpharmakologischen Anwendungen wurden analysiert. Zusätzlich wurden Kennzahlen des BCC mit Auswertungen des nationalen Jahresberichtes 2016 zertifizierter BCC verglichen. Ergebnisse: Im Zeitraum 2011-2016 wurden 741 primäre Brustkrebspatienten (medianes Alter bei Diagnosestellung 57,4 Jahre) am GKH BCC behandelt. 91,5\% der Patienten wiesen Tumoren der Union for International Cancer Control (UICC)-Stadien 0, I, II oder III auf und 8,2\% der Patienten hatten Tumoren im Stadium IV. $97 \%$ der Patienten wurden operiert, $53 \%$ erhielten eine Bestrahlung, 38\% der Patienten wurden antihormonell und $25 \%$ zytostatisch behandelt. 96\% der Patienten erhielten nichtpharmakologische Anwendungen und 32\% eine Therapie mit Viscum album L. Für bis zu 93\% der Patienten konnten 2 Jahre nach Diagnosestellung Nachbeobachtungsdaten erhoben werden. Im nationalen Vergleich zu zertifizierten BCC erfüllte das GKH BCC die zentralen Anforderungen. Schlussfolgerungen: Die Ergebnisse der vorliegenden Studie zeigen, dass die im Rahmen der anthroposophischen Medizin angebotenen integrativen Therapien in die tägliche Krankenhausversorgung eines zertifizierten BCC implementiert werden können. Aufgrund fehlender nationaler Leitlinien zu integrativen Ansätzen in der Onkologie bedarf es weiterer Studien zur systematischen Evaluation integrativer Therapieverfahren und Versorgungskonzepte.

\section{KARGER}

Fax +497614520714 Information@Karger.com www.karger.com

2018 The Author(s)
Published by S. Karger GmbH, Freiburg
Open acer

This article is licensed under the Creative Commons AttributionNonCommercial-NoDerivatives 4.0 International License (CC BY-NCND 4.0) (http://www.karger.com/Services/OpenAccessLicense). Usage for commercial purposes as well as any distribution of modified material requires written persis as wer.
Dr. med. Friedemann Schad

Gemeinschaftskrankenhaus Havelhöh

Kladower Damm 221, 14089 Berlin, Germany

fschad@ havelhoehe.de 


\section{Introduction}

In recent decades the concept of integrative medicine (IM) has attracted growing interest in patients and professionals, both scientists and practitioners [1-4]. The Education Working Group of the Consortium of Academic Health Centers for Integrative Medicine (CAHCIM) indicates IM 'as an approach to the practice of medicine that makes use of the best-available evidence, taking into account the whole person (body, mind, and spirit), including all aspects of lifestyle' [5]. Reasons for the use and need of integrative treatment options in oncology have been described previously and include cure or prolongation of life, symptom relief from cancer and its treatment, boost of immunological functions, enhancement of physical, emotional, and or spiritual well-being, as well as maintenance of control over cancer and its treatment [6-13]. Further reasons might be the perception that IM is more natural and beneficial and will cause no harm; dissatisfaction with conventional treatment alone; and congruency between the patients' philosophical values and the paradigms proposed by IM treatment $[2,14,15]$.

Anthroposophical medicine as an IM system is based on scientific standards and guidelines of conventional medicine but integrates a range of treatment options like naturopathy remedies and non-pharmacological interventions (NPIs), including mindfulness-orientated movement therapies (e.g., eurythmy therapy), mind-body procedures, art therapies, and nursing interventions [9, 16-20]. The aim is to promote the physical and psychological salutogenic powers and resources of the patient, to improve the healthrelated quality of life (HRQL) and to support social and spiritual needs. A special focus is set on coping strategies, shared decisionmaking, and the patients' individual health aims.

The German 'National Cancer Plan' was established between the years 2008 and 2010 [21], implementing certified organ and cancer centers (CCs). CCs are specialized departments with guideline-oriented high-standard procedures; they comprise at least 3 organ-specific centers, demanding widespread structural and professional expertise [21-23]. The Gemeinschaftskrankenhaus Havelhöhe (GKH) as a general hospital and certified CC offers primary and secondary care and patient-centered anthroposophical medicine for oncological patients. The Department of Gynecology and Obstetrics at the GKH has been successfully certified as a breast cancer center (BCC) since 2012. BCCs have to meet specified requirements based on an approved quality management system. Diagnostic procedures and treatment have to be in accordance with the guidelines of the German Cancer Society (Deutsche Krebsgesellschaft, DKG), the German Cancer Aid (Deutsche Krebshilfe, DKH), and the Working Group of Scientific Medical Societies (Arbeitsgemeinschaft der wissenschaftlichen medizinischen Fachgesellschaften, AWMF). Psycho-oncological and social support must be offered and continuous medical and scientific training of the staff is mandatory. The central organization is the weekly interdisciplinary tumor board involving experts from all relevant oncological disciplines for consented treatment recommendations. Patients must be followed up at 6-month intervals to gain complete documentation of the treatment history. National benchmarking data analyses are regularly published by the DKG [23].
Table 1. Baseline characteristics of the primary breast cancer patients

\begin{tabular}{ll}
\hline Characteristic & Value \\
\hline Number of cases, total, n (\%) & $768(100)^{\mathrm{a}}$ \\
$\quad$ Right breast, $\mathrm{n}(\%)$ & $373(48.6)$ \\
Left breast, $\mathrm{n}(\%)$ & $395(51.4)$ \\
Left and right breast, $\mathrm{n}(\%)$ & $27(3.5)$ \\
Number of patients, total, n (\%) & $741(100)$ \\
Age, years, median (IQR) & $57.4(49.3-69.9)$ \\
Gender, male, n (\%) & $2(0.3)$ \\
UICC stage ${ }^{\mathrm{b}}, \mathrm{n}(\%)$ & \\
0 & $64(8.6)$ \\
I & $266(35.9)$ \\
II & $253(34.1)$ \\
III & $95(12.8)$ \\
IV & $61(8.2)$ \\
NA & $2(0.3)$ \\
\hline
\end{tabular}

aprimary breast cancer cases $(\mathrm{N}=768)$ in 741 patients at the day of first diagnosis. ${ }^{\mathrm{b}}$ At the day of first diagnosis.

$\mathrm{IQR}=$ Interquartile range; UICC = Union for International Cancer Control; $\mathrm{NA}=$ not available.

In the present study, we evaluated therapy data of breast cancer patients (C50, D05 diagnosis) who were primarily diagnosed and treated in the certified BCC of the GKH, and analyzed how integrative strategies were implemented. First comparisons of quality measures and outcome items between our BCC and nationwide benchmarking BCCs are shown.

\section{Methods}

Subject Population

Primary breast cancer cases were denoted according to the German certifier OnkoZert:

- Time point of count is the time of primary diagnosis

- Patients and not hospital stays or surgeries

- Each breast is counted as a primary case

- Ductal carcinoma in situ (DCIS) cases are counted as primary cases

- Cases count only for 1 center

- Breast carcinomas of men and primary M1 patients are also counted as primary cases

- Histological report must be available

- Planning of therapy (interdisciplinary tumor board) and therapy realization is accomplished by the BCC (primary therapy)

According to the certification guidelines, the number of primary cases is not necessarily equal to the number of primary patients since more than 1 primary breast cancer case can be attributed to 1 primary breast cancer patient.

\section{Data Source and Assessment}

Clinical and demographic data were retrieved from the local hospital database. Documented TNM (tumor/node/metastasis) stages or metastases were queried with their according date and translated into Union for International Cancer Control (UICC) stages according to the 7th edition of the 'TNM Classification of Malignant Tumours' [24]. The disease stage was described according to UICC staging. Conventional therapies including chemotherapy, surgery, or radiation were queried with their according date. Surgical interventions were coded according to the German procedure classification 2013 [25]. Time frame and applied pharmaceuticals of systemic therapies including chemotherapy, 
Table 2. NPIs applied in the primary breast cancer patients $(\mathrm{N}=712)$ between January 2011 and June 2016

\begin{tabular}{lc}
\hline Non-pharmacological intervention (NPI) & Patients, $\mathrm{n}(\%)$ \\
\hline All NPIs & $712(100)$ \\
Art therapies & $562(78.9)$ \\
Breathing therapy & $6(0.8)$ \\
Education/training including dietary training & $564(79.2)$ \\
Massages including organ embrocations and lymph drainage & $695(97.6)$ \\
Movement therapies including eurythmy therapy, physiotherapy & $639(89.7)$ \\
Nursing interventions including compresses, embrocations, and therapeutic baths & $622(87.4)$ \\
Psycho-oncological support & $679(95.4)$ \\
\hline
\end{tabular}

targeted therapy, and mistletoe (Viscum album L. = VA) therapy were documented. Detailed information on the amount and time of NPIs per patient was obtained. Numbers of contacted patients and of visits during follow-up were retrieved from the surveillance and study center. Continuous variables were described as median with interquartile range (IQR); categorical variables were summarized as frequencies and percentages. Data distributions were validated with graphical inspections by box plot, QQ (quantile-quantile) plot, and histograms and were arithmetically examined by skewness. Descriptive analysis was used to perform comparisons between BCC and benchmarking centers.

Comparison with Nationwide Cancer Standards

Various quality measures (2011-2015) from the GKH BCC were compared with data of the Breast Cancer Benchmarking Report 2016, covering quality measures from the years 2011-2014 from 275 certified nationwide BCCs in Germany ( $\mathrm{n}=52,965$ patients) [23]. Comparisons between BCC and benchmarking data were descriptively evaluated. The quota for compliance is set each year by the DKG and the DKH.

\section{Results}

Between January 1, 2011 and June 30, 2016, 897 breast cancer patients were treated at the BCC of the GKH. Among them were 741 primary breast cancer patients representing 768 primary breast cancer cases (table 1). Two patients were male. The median age was 57.4 years (IQR $=49.3-69.9$ years). In 395 cases (51.4\% of the primary cases), the left, and in 373 cases ( $48.6 \%$ of the primary cases), the right breast was affected. 27 patients $(3.5 \%$ of the primary cases) had bilateral cancer. $91.5 \%$ of the patients showed UICC stage 0 , I, II, or III, and $8.2 \%$ had metastasis at first diagnosis (UICC stage IV). In $0.3 \%$ of the patients, staging was not completed at database closure. 46 patients $(6.2 \%)$ had secondary cancer diagnoses in their medical records, revealing gastrointestinal (26.1\%), gynecological (19.6\%), and skin tumors (17.4\%) as the most common neoplasms.

The clinical management of the GKH BCC involves the processes of registration, consultations, hospital admission, inpatient stay, and dismissal of the patient according to the S3 guideline for the 'diagnosis, therapy and follow-up of mamma carcinoma' [26] and is briefly described hereafter. After first contact, the patient will be informed within $24 \mathrm{~h}$ on their appointment with the BCC. During the first and second appointments with the patient in the BCC, the responsible physician thoroughly evaluates the patient's medical history, discusses with them their personal expectations and emotional status, checks existing medical documents, arranges first appointments with relevant specialists (e.g. oncologists, psycho-on- cologists) and discusses medical standard and add-on treatment options with the patient. In addition, the patient will be registered for the upcoming interdisciplinary weekly tumor board conference, which engages a gynecological breast surgeon, a plastic surgeon, a radiologist, a medical oncologist, and radiation therapists. Optionally, a psycho-oncological professional and a nursing specialist are part of the conference. The patient also has the chance to participate in the tumor board, as the GKH actively supports shared decision-making. The tumor board panel releases a joint recommendation for the therapy of the patient. At the patient's hospital admission, nursing and medical anamnesis as well as a physical examination, blood retrieval for laboratory assessments, an electrocardiogram (for patients $>40$ years), a chest X-ray scan (for patients with sentinel lymph node labeling), and a pre-anesthesia consultation (for patients receiving surgery) are performed. The patient will also be informed on post-treatment and follow-up surveillance procedures. Furthermore, appointments with social services, psychooncological professionals, and NPI therapists are arranged at day 1 of hospital admission. NPIs include art therapy (music, painting, and modeling), breathing therapy, rhythmical massages, nursing interventions (e.g. compresses, embrocations, and therapeutic bathes), movement therapy (eurythmy therapy and physiotherapy), and educational programs and dietary training (table 2). During the hospital stay, the patient receives standard therapies in conjunction with integrative ones. Personalized add-on therapies are listed on a structured weekly plan, which is handed out to the patient. Analogous to complex treatments in palliative care (national OPS code 8-982 (German surgical operation and procedure classification)), chronic pain (OPS code 8-918), and natural medicine (OPS code 8-975.2) where specific minimal criteria must be obeyed, an additional payment for integrative anthroposophical complex treatments (national OPS code 8-975.3) is granted by health insurance companies if at least 30 therapeutic units are documented for the patient within 1 hospital stay [27]. In a weekly inter-professional patient conference, the therapeutic interventions of each patient are discussed among physicians, nurses, and therapists. Personal consultations between physician and patient, lasting on average more than $30 \mathrm{~min}$, are regularly held during the hospital stay and include a biographical dialogue, explanation of findings, and/or information on the utilization of integrative therapies. The above-described processes are documented in the CC and BCC quality management manual (Handbuch Onkologisches Zentrum Havelhöhe), which is updated annually (last version, June 2016). 
Table 3. Surgical interventions in the primary breast cancer patients $(\mathrm{N}=741)$ at the first hospital stay

\begin{tabular}{|c|c|c|c|}
\hline Surgical intervention & OPS number & $\begin{array}{l}\text { Interventions, } \\
\mathrm{n}(\%)\end{array}$ & $\begin{array}{l}\text { Patients, } \\
\mathrm{n}(\%)\end{array}$ \\
\hline All & $5-87^{\star}, 5-88$ & $857(100)$ & $722(100)$ \\
\hline Partial excision of the tumor without axillary lymphadenectomy & $5-870$ & $649(75.7)$ & $569(78.8)$ \\
\hline Partial excision of the tumor with axillary lymphadenectomy & $5-871$ & $32(3.7)$ & $32(4.4)$ \\
\hline Mastectomy without axillary lymphadenectomy & $5-872$ & $135(15.8)$ & $128(17.7)$ \\
\hline Mastectomy with axillary lymphadenectomy & $5-873$ & $13(1.5)$ & $13(1.8)$ \\
\hline Subcutaneous mastectomy and other skin-preserving mastectomies & $5-877$ & $10(1.2)$ & $9(1.2)$ \\
\hline Other excisions or resections & $5-879$ & $1(0.1)$ & $1(0.1)$ \\
\hline Incision of the tumor & $5-881$ & $6(0.7)$ & $6(0.8)$ \\
\hline Other plastic surgeries of the breast & $5-886$ & $3(0.4)$ & $3(0.4)$ \\
\hline Other surgeries of the breast & $5-889$ & $2(0.2)$ & $2(0.3)$ \\
\hline Lymph node excision, total & $5-401^{\star}, 5-407^{\star}$ & $64(100)$ & $62(100)$ \\
\hline
\end{tabular}

OPS = German surgical operation and procedure classification.

Some of the procedures were simultaneously or subsequently performed in one and the same patient; therefore, they do not add up to $100 \%$.
The following results reflect the number of patients that received guideline-oriented standard therapies and/or additive integrative therapies comprising VA therapy and non-pharmacological interventions. Of 741 primary breast cancer patients, 722 patients (96.8\%) underwent breast surgery, mainly breast-preserving partial excision of the mamma or tissue destruction without axillary lymph node dissection (table 3). A total of 396 (53.4\%) patients received radiation (table 4). In 383 of these patients ( $96 \%$ of the patients with radiation), the primary tumor region was radiated, while in 58 patients (14.6\%), lymph node metastases, and in 17 patients $(4.3 \%)$, distant metastases were radiated.

Of 741 primary breast cancer patients, $280(37.7 \%)$ received hormone therapy, $63(8.5 \%)$ received a targeted or immune-modulating therapy, and $31(4.2 \%)$ received bisphosphonates (table 4 ). $188(25.3 \%)$ of the primary breast cancer patients received cytostatic drugs. 123 of these (65.4\%) received cyclophosphamide, 113 epirubicin (60.1\%), and 87 paclitaxel (46.3\%; data not shown). The most frequently applied systemic cytostatic drug combinations were cyclophosphamide/epirubicin $(\mathrm{n}=113,60.1 \%)$, 5-fluorouracil/cyclophosphamide/epirubicin ( $\mathrm{n}=17,9.0 \%$ ), and cyclophosphamide/doxorubicin ( $\mathrm{n}=9,4.8 \%$; data not shown). 741 patients had 1 hospital stay, 247 of them (33.3\%) 2 stays, 63 (8.5\%) 3 stays, 29 (3.9\%) 4 stays, and 24 (3.2\%) more than 5 hospital stays. The average time the patient spent in hospital was, in median, 7 days during the first hospital stay.

One-third of the patients received VA therapy ( $\mathrm{n}=238,32.1 \%$; table 4 ). While most patients received VA therapy subcutaneously ( $n=204,85.7 \%), 68$ (28.6\%) also received off-label use intravenous VA application (data not shown).

712 of 741 primary breast cancer patients $(96.1 \%)$ received multimodal NPIs (table 2). 707 patients (99.3\% of the patients who received NPIs) had at least 2 NPIs. The median number of applied NPIs was 12, with an IQR of 9-14 NPIs (data not shown). 595 patients (83.6\% of the patients who received NPIs) had between 5 and 15 various NPIs (median number of NPIs $11, \mathrm{IQR}=2-39 \mathrm{NPIs}$ ). The most frequent NPIs were massage (97.6\%), psycho-oncological
Table 4. Radiation and anti-neoplastic treatments in the primary breast cancer patients during the study period

\begin{tabular}{lc}
\hline Treatment & $\mathrm{n}\left(\%{ }^{\mathrm{a}}\right)$ \\
\hline Radiation & $396(53.4)$ \\
Primary tumor & $383(51.7)$ \\
Metastatic lymph nodes & $58(7.8)$ \\
Distant metastases & $17(2.3)$ \\
Anti-neoplastic treatment & \\
Hormone therapy & $280(37.8)$ \\
Cytostatic drugs & $188(25.3)$ \\
Targeted or immune-modulating therapy & $63(8.5)$ \\
Bisphosphonates & $31(4.2)$ \\
VA therapy & $238(32.1)$ \\
\hline
\end{tabular}

${ }^{\mathrm{a}}$ As percent of $\mathrm{N}=741$ primary breast cancer patients.

$\mathrm{VA}=$ Viscum album $\mathrm{L}$.

support (95.4\%; e.g., psycho-education, psychotherapy, crisis intervention), movement therapies (89.7\%; eurythmy therapy, physiotherapy), and nursing interventions (87.4\%; e.g., compresses, embrocation, therapeutic baths; table 2 ).

Follow-up of patients was performed in $95.8 \%$ of all primary breast cancer patients 6 months after primary diagnosis (i.e., $100 \%$ compliance in patients contacted at day 0 ), in $94.4 \%$ of all primary patients 1 year after primary diagnosis (i.e., $98.6 \%$ compliance in patients contacted at 6 months), and in $93.1 \%$ of all primary patients 2 years after primary diagnosis (i.e., $97.1 \%$ compliance in patients contacted at 1 year).

To gain a first impression of the nationwide performance of the GKH BCC, a comparison between appropriate quality measures of the GKH BCC and nationwide benchmarking BCCs was conducted (table 5). Data were retrieved from the annual benchmarking report 2016, which summarizes the nationwide quality measures from 275 certified BCCs and 52,965 patients in Germany [23]. All requirements set by the DKG and DKH were met, except for the item 'determination of nodal status in invasive breast cancer 
Table 5. Comparison of the quality measures ${ }^{\mathrm{a}}$

\begin{tabular}{lccl}
\hline Quality measure & $\begin{array}{l}\text { GKH BCC: } \\
\text { Median }{ }^{\mathrm{b}}, \%\end{array}$ & $\begin{array}{l}\text { Benchmark: } \\
\text { Median }^{c}, \%\end{array}$ & $\begin{array}{l}\text { Required } \\
\text { quota }^{\mathrm{d}}, \%\end{array}$ \\
\hline Postoperative case discussion & 100 & 100 & $\geq 95$ \\
Pre-therapeutic case discussion & 88 & 54.1 & no specifications \\
Psycho-oncological support & 93 & 69.0 & no specifications \\
Social service consultation & 80 & 88.3 & no specifications \\
Patients enrolled in studies & 49 & 14.1 & $\geq 5$ \\
Breast-preserving surgery in the pT1 stage & 95 & 84.5 & $70-90$ \\
Determination of the nodal status in & 94 & 97.8 & $\geq 95$ \\
$\quad$ invasive breast cancer patients & & & $\geq 80$ \\
Sentinel lymph node removal at pN0 & 83 & 95.2 & $\leq 5$ \\
Revision surgeries & 2 & 2.8 & no specifications \\
Postoperative wound infections & 0.45 & 1.4 & \\
\hline
\end{tabular}

${ }^{\text {a }}$ Quality measures of the BCC GKH compared to those of the 275 nationwide BCCs ( $N=52,965$ patients) as published in the Breast Cancer Benchmarking Report 2016.

bGKH: 2011-2015.

${ }^{\mathrm{C} B e n c h m a r k i n g ~ r e p o r t: ~ 2011-2015 . ~}$

${ }^{\mathrm{d}}$ Quota set by the German Cancer Association (DKG) and the German Cancer Aid (DKH).

$\mathrm{BCC}=$ Breast cancer center; $\mathrm{GKH}=$ Gemeinschaftskrankenhaus Havelhöhe.

patients', which was just short of meeting the requirements $(1 \%$ below the quota). The quotas of pre-therapeutic case discussion (33.9\% difference), psycho-oncological support (24\% difference), patients enrolled in studies (34.9\% difference), and breast-preserving surgery in the pT 1 stage ( $10.5 \%$ difference) were above the nationwide benchmarking average. The quota of social service consultation ( $8.3 \%$ difference) was below the benchmarking level; however, no quota was specified for this item by the DGK and DKH. In 'sentinel lymph node removal', the GKH BCC was also below the benchmarking average. However, the median of the past 5 years $(83 \%)$ was above the required quota $(>80 \%)$. Furthermore, the median for this item in 2015 at the BCC was $89.3 \%$, indicating a trend towards increment in this quality item. In the item 'patients enrolled in study' the GKH BCC was $44 \%$ above the required quota and $35 \%$ above the benchmarking level. In 'revision surgeries' ( $0.8 \%$ difference) and 'post-surgical wound infections' (1.05\% difference), the BCC GKH was below the benchmarking average, indicating high-quality management. In 'post-surgical case discussion', the BCC GKH had reached $100 \%$, equal to the level of the benchmarking BCCs.

\section{Discussion}

The 'National Cancer Plan' in Germany highlights basic fields in cancer treatment: development of early detection of cancer, provision of quality assurance systems, development of clinical structures securing efficient cancer treatment, and empowerment of patient orientation [21]. The GKH as a certified CC contributes to key elements of the National Cancer Plan and additionally applies integrative therapies within a patient-centered context. In our BCC, 741 primary breast cancer patients were discussed between January 2011 and June 2016 in the weekly interdisciplinary tumor board. Conventional therapies (e.g., surgery, chemotherapy, hor- mone therapy, and radiation) were recommended and applied regularly in accordance with the national S3 treatment guidelines. In addition, as shown by our data, integrative therapies play a significant role in the therapeutic concept and in the daily care of the BCC.

Breast cancer patients show a high need for psychological attendance [28]. In our cohort, $94 \%$ of the patients had psycho-oncological support. It is well accepted and part of the national cancer program to emphasize the importance of psycho-oncological interventions and communication in cancer care. Therefore, it was integrated as a requirement in BCC audits [29]. In contrast to the widespread requirements and practical use, there are generally very low numbers of statements and recommendations on supportive or psychosocial therapies and integrative therapies in the German oncological guidelines [30]. It has been shown in prospective studies that emotional functioning, including less anxiety, stress, and depression, has a positive influence on the overall survival in patients with metastasized breast cancer [31, 32]. In a randomized study in patients with gastrointestinal tumors and psychotherapeutic support after primary surgery, a benefit in terms of long-term survival was described [33]. In lung cancer, a concept of early palliative care, which included periodical talks with a professional, Temel et al. [34] showed a prolongation of overall survival and an improvement in HRQL. For breast cancer patients and for patients with other cancer entities, it was shown that the HRQL is prognostic for and predictive of survival [31, 32, 35-37]. Psychological support as part of palliative care has become an indispensable factor in palliative cancer treatment [38] and, recently, effective transfer and optimization of communications skills were shown [39].

Our patients were 6.6 years younger than the German average [40]. It is well known that women of a younger age are more interested in complementary therapies as part of IM [3, 41]. In our center, a high percentage of patients underwent nursing interventions like embrocation, massage, and compresses, which play a 
major role as therapeutic instruments in anthroposophical nursing $[18,19]$. Besides psycho-oncological support and massages as the most frequent NPIs in the primary breast cancer patients in the present study, movement therapies including eurythmy therapy and physiotherapy are very often applied. Overall, almost every inpatient received at least 2 NPIs (99\%) and the majority (78\%) had between 5 and 15 NPIs. The different distributions of therapies are influenced by the therapeutic concept, the individualized indication, by the patient's cooperation and expectation, and by different available resources.

The comparison of the outcome measures between our BCC and the nationwide benchmarking report shows good results while the annual formal requirements were met in all central items during the past 5 years. The items presented here reflect key quality measures from the specification catalogue of the DKG and DKH, which were in the focus during the certifications and annual reaudits procedures. In order to retain a first picture within the landscape of certified BCCs, they provide aspects in which the GKH BCC performed well or better than the required quota (e.g., psycho-oncological support, breast-preserving surgeries) and outcome items in which our BCC will need to improve (e.g., social services, sentinel lymph node removal at $\mathrm{pN} 0$ ).

Integrative oncology has been developed over decades and is established in US American academic structures and leading cancer centers $[9,42]$. Even evidence-based clinical practice guidelines for integrative oncology were defined [10]. Although there are growing efforts in research on anthroposophical clinical concepts, the systematic evaluation of anthroposophical-integrative oncology is in an early stage. Therefore, we established a surveillance and study center to evaluate the patients' needs and outcomes. We document good compliance, with contact being maintained with over $93 \%$ of the patients even after 2 years of follow-up. Since 2012, we have been collecting HRQL data using psychometric instruments after discharge. Preliminary results of our group have shown positive ef- fects on the HRQL, including emotional and social functioning in primary breast cancer patients treated within an anthroposophicalintegrative concept [43]. This is in line with a prospective, multicenter trial with 105 non-metastasized breast cancer patients, where a 10 -week multimodal program including psycho-education, eurythmy, and painting therapy significantly reduced fatigue/ disturbed sleep, showing superiority over aerobic training in an exploratory analysis [44]. International studies indicate a high interest in IM of breast cancer patients. In the future, conventional outcome parameters may be more complemented with patientorientated outcome measures.

\section{Conclusions}

The results of the present study reveal a high use of integrative therapies in the treatment of primary breast cancer patients and their successful integration into the clinical practice of a certified BCC. The GKH BCC performs well in central items of quality measures compared to the nationwide benchmarking BCCs in Germany. Patient adherence seems to be strong, and further evaluation of patient-reported outcome data is to be expected in the following years.

\section{Acknowledgement}

We would like to thank all staff members at the GKH and the Forschungsinstitut Havelhöhe involved in the present work.

\section{Disclosure Statement}

The authors declare no competing interests.

\section{References}

1 Horneber M, Bueschel G, Dennert G, et al: How many cancer patients use complementary and alternative medicine: a systematic review and metaanalysis. Integr Cancer Ther 2012;11:187-203.

2 Klafke N, Eliott JA, Wittert GA, et al: Prevalence and predictors of complementary and alternative medicine (CAM) use by men in Australian cancer outpatient services. Ann Oncol 2012;23:1571-1578.

3 Molassiotis A, Fernadez-Ortega P, Pud D, et al: Use of complementary and alternative medicine in cancer patients: a European survey. Ann Oncol 2005;16:655-663.

4 Lim E, Vardy JL, Oh B, et al: Comparison of integrative medicine centers in the USA and Germany: a mixed method study. Support Care Cancer 2017;25:1865-1872.

5 Kligler B, Maizes V, Schachter S, et al: Core competencies in integrative medicine for medical school curricula: a proposal. Acad Med 2004;79:521-531.

6 Shalom-Sharabi I, Samuels N, Lavie O, et al: Effect of a patient-tailored integrative medicine program on gastro-intestinal concerns and quality of life in patients with breast and gynecologic cancer. J Cancer Res Clin Oncol 2017;143:1243-1254.
7 Standish LJ, Dowd F, Sweet E, et al: Breast cancer integrative oncology care and its costs. Integr Cancer Ther 2017;16:85-95.

8 Sagar SM: Integrative oncology: are we doing enough to integrate psycho-education? Future Oncol 2016;12: 2779-2783.

9 Sagar SM: Integrative oncology in North America. J Soc Integr Oncol 2006;4:27-39.

10 Deng GE, Frenkel M, Cohen L, et al: Evidence-based clinical practice guidelines for integrative oncology: complementary therapies and botanicals. J Soc Integr Oncol 2009; 7:85.

11 Axtner J, Steele M, Kroz M, et al: Health services research of integrative oncology in palliative care of patients with advanced pancreatic cancer. BMC Cancer 2016;16:579.

12 Frass M, Friehs H, Thallinger C, et al: Influence of adjunctive classical homeopathy on global health status and subjective wellbeing in cancer patients - a pragmatic randomized controlled trial. Complement Ther Med 2015;23:309-317.
13 Rostock M, Naumann J, Guethlin C, et al: Classical homeopathy in the treatment of cancer patients a prospective observational study of two independent cohorts. BMC Cancer 2011;11:19.

14 Pirri C: Integrating complementary and conventional medicine. Cancer Forum, The Cancer Council Australia, www.cancerforum.org.au, 2011.

15 Furnham A, Smith C: Choosing alternative medicine: a comparison of the beliefs of patients visiting a general practitioner and a homoeopath. Soc Sci Med 1988;26: 685-689.

16 Hanaway P: Systems approaches: a global and historical perspective on integrative medicine. Global Adv Health Med 2012;1:10-11.

17 Kienle GS, Albonico H-U, Baars E, et al: Anthroposophic medicine: an integrative medical system originating in Europe. Global Adv Health Med 2013;2:2031.

18 Hack CC, Hüttner N, Paepke D, et al: Integrative Medizin in der Gynäkologischen Onkologie - Möglichkeiten und Grenzen Teil 1. Geburtshilfe Frauenheilkd 2013; 73:R63-R80. 
19 Paepke D, Klein E, Paepke S, et al: Anthroposophie und Homöopathie in der Integrativen Medizin. Frauenheilkd up2date 2014;8:115-130.

20 Kienle GS, Kiene H, Albonico H-U: Anthroposophische Medizin: Health Technology Assessment Bericht Kurzfassung. Forsch Komplementmed 2006;13:11

21 Bundesministerium für Gesundheit: Aktueller Stand des Nationalen Krebsplans. Handlungsfelder, Ziele und Umsetzungsempfehlungen. https://www.bundesgesundheitsministerium.de/fileadmin/Dateien/3_Downloads/ N/Nationaler_Krebsplan/Nationaler_Krebsplan-Zieluebersicht.pdf, 2012 (last accessed June 9, 2017).

22 Deutsche Gesellschaft für Senologie und Deutsche Krebsgesellschaft: Jahresbericht 2015. Brustkrebszentren (Stand 21.07.2016), Version A3. www.onkozert.de/ aktuelles_150326.htm, 2016 (last accessed June 9, 2017).

23 Deutsche Gesellschaft für Senologie und Deutsche Krebsgesellschaft: Kennzahlen Brustkrebszentren. Stand 19.10.2016. www.onkozert.de/aktuelles_150326. htm, 2016 (last accessed June 9, 2017).

24 Sobin LH, Gospodarowicz MK, Wittekind C: TNM Classification of Malignant Tumours, ed 7. New York, John Wiley \& Sons, 2011.

25 Deutsches Institut für Medizinische Dokumentation und Information: Operationen- und Prozeduren schlüssel: Version 2013. http://www.dimdi.de/static/de/ klassi/ops/kodesuche/onlinefassungen/opshtml2013/ index.htm.

26 DKG (Deutsche Krebsgesellschaft), DKH (Deutsche Krebshilfe), AWMF (Arbeitsgemeinschaft der wissenschaftlichen medizinischen Fachgesellschaften): Interdisziplinäre S3-Leitlinie für die Diagnostik, Therapie und Nachsorge des Mammakarzinoms. Leitlinienprogramm Onkologie. Langversion 3.0, Aktualisierung 2012 AWMF Register Nummer 032 - 045OL, 2012.
Heinz J, Fiori W, Heusser P, et al: Cost analysis of integrative inpatient treatment based on DRG data: the example of anthroposophic medicine. Evid Based Complement Alternat Med 2013;2013:748932.

28 Thewes B, Butow P, Girgis A, et al: The psychosocial needs of breast cancer survivors; a qualitative study of the shared and unique needs of younger versus older survivors. Psychooncology 2004;13:177-189.

29 Deutsche Gesellschaft für Senologie: Erhebungsbogen für Brustkrebszentren der Deutschen Krebsgesellschaft. Version 14.07.2016. https://www.senologie.org, 2016.

30 Huebner J, Follmann M: Complementary medicine in guidelines of the German Guideline Program in Oncology: comparison of the evidence base between complementary and conventional therapy. J Cancer Res Clin Oncol 2013;139:1481-1488.

31 Coates AS, Hurny C, Peterson HF, et al: Quality-of-life scores predict outcome in metastatic but not early breast cancer. International Breast Cancer Study Group. J Clin Oncol 2000;18:3768-3774.

32 Groenvold M, Petersen MA, Idler E, et al: Psychological distress and fatigue predicted recurrence and survival in primary breast cancer patients. Breast Cancer Res Treat 2007;105:209-219.

33 Küchler T, Bestmann B, Rappat S, et al: Impact of psychotherapeutic support for patients with gastrointestinal cancer undergoing surgery: 10-year survival results of a randomized trial. J Clin Oncol 2007;25:2702-2708.

34 Temel JS, Greer JA, Muzikansky A, et al: Early palliative care for patients with metastatic non-small-cell lung cancer. N Engl J Med 2010;363:733-742.

35 Pinheiro LC, Zagar TM, Reeve BB: The prognostic value of pre-diagnosis health-related quality of life on survival: a prospective cohort study of older Americans with lung cancer. Qual Life Res 2017;26:1703-1712.

36 Kypriotakis G, Vidrine DJ, Francis LE, et al: The longitudinal relationship between quality of life and survival in advanced stage cancer. Psychooncology 2016;25: 225-231.
37 Peters KB, West MJ, Hornsby WE, et al: Impact of health-related quality of life and fatigue on survival of recurrent high-grade glioma patients. J Neurooncol 2014;120:499-506

38 Smith TJ, Temin S, Alesi ER, et al: American Society of Clinical Oncology provisional clinical opinion: the integration of palliative care into standard oncology care. J Clin Oncol 2012;30:880-887.

39 Merckaert I, Delevallez F, Gibon A-S, et al: Transfer of communication skills to the workplace: impact of a 38 hour communication skills training program designed for radiotherapy teams. J Clin Oncol 2015;33:901-909.

40 Ostermann T, Raak C, Bussing A: Survival of cancer patients treated with mistletoe extract (Iscador): a systematic literature review. BMC Cancer 2009;9:451.

41 Fremd C, Hack CC, Schneeweiss A, et al: Use of complementary and integrative medicine among German breast cancer patients: predictors and implications for patient care within the PRAEGNANT study network Arch Gynecol Obstet 2017;295:1239-1245.

42 Vohra S, Feldman K, Johnston B, et al: Integrating complementary and alternative medicine into academic medical centers: experience and perceptions of nine leading centers in North America. BMC Health Serv Res 2005;5:78

43 Thronicke A, Kröz M, Steele M, et al: Health status and health related quality of life of breast cancer patients receiving multimodal integrative concepts within health services research of a certified Breast Cancer Centre. Forum 2017;32:96 (abstr). https://doi.org/ 10.1007/s12312-017-0215-0.

44 Kroz M, Reif M, Glinz A, et al: Impact of a combined multimodal-aerobic and multimodal intervention compared to standard aerobic treatment in breast cancer survivors with chronic cancer-related fatigue - results of a three-armed pragmatic trial in a comprehensive cohort design. BMC Cancer 2017;17:166. 